\title{
DOCUMENTAÇÃO DO PORTUGUÊS FALADO EM COMUNIDADES RURAIS AFRO-BRASILEIRAS DE SERGIPE: PATRIMÔNIO E MEMÓRIA
}

\author{
José Humberto dos Santos Santana \\ Mestrando em Letras pela Universidade Federal de Sergipe(UFS) \\ humbertosantana88@hotmail.com
}

Silvana Silva de Farias Araujo Doutora em Língua e Cultura pela Universidade Federal da Bahia (UFBA) Professora Adjunta da Universidade Estadual de Feira de Santana(UEFS) silvana.UEFS.2014@gmail.com

Raquel Meister Ko Freitag Doutora em Linguística pela Universidade Federal de Santa Catarina (UFSC) Professora Associada da Universidade Federal de Sergipe(UFS) rkofreitag@uol.com.br

\begin{abstract}
RESUMO
No cenário sociolinguístico brasileiro, a diversidade linguística é um tema que precisa ser discutido e aprofundado, antes que a padronização e a normatização das variedades linguísticas brasileiras, especialmente das que são faladas fora dos grandes centros e em grupos minoritários rurais, apaguem as principais características do vernáculo brasileiro popular. Urge, assim, que sejam realizadas pesquisas de documentação, descrição e análise do português falado nessas comunidades. Com este artigo, chamamos a atenção para a importância do mapeamento e documentação do português falado em comunidades rurais afro-brasileiras sergipanas, variedade linguística que ainda não foi alvo de estudos sistemáticos. Ao longo do texto, ressaltamos a importância da realização de pesquisas regionais com o desenvolvimento de métodos específicos para as regiões em foco.
\end{abstract}

Palavras-chave: comunidades quilombolas, constituição de amostras de fala sociolinguísticas, Inventário Nacional da Diversidade Linguística (INDL).

\begin{abstract}
On the Brazilian sociolinguistic scenario, the linguistic diversity is a theme that needs to be discussed and deepened, before the regularization and standardization of the Brazilian linguistic varieties, especially of those spoken outside the large centers and in rural minority groups, erase the main characteristics of the Brazilian popular vernacular. It is necessary, therefore, to implement researches of documentation, description and analysis of the Portuguese spoken at these communities. With this article, we attract the attention to the importance of the mapping and documentation of the Portuguese spoken in Afro-Brazilian rural communities of the state of Sergipe, linguistic variety that was not yet object of systematic studies. Throughout the text, we highlight the importance of the implementation of regional researches with the development of specific methods for the regions in focus.
\end{abstract}

Keywords: Afro-Brazilian rural communities, formation of sociolinguistic speech samples, National Inventory of the Linguistic Diversity (INDL). 


\section{Introdução}

A Sociolinguística é o campo disciplinar que estuda a relação entre língua e sociedade. No cenário brasileiro, muito esforço investigativo tem sido dedicado ao registro e descrição das variedades do português, do ponto de vista científico, visando caracterizá-las quanto às dimensões sociais e regionais. No entanto, mais recentemente, com o Inventário Nacional da Diversidade Linguística (INDL), do Instituto do Patrimônio Histórico e Artístico Nacional, vinculado ao Ministério da Cultura, abre-se a possibilidade de, ao mesmo tempo em que se estuda a língua como objeto de pesquisa científica de descrição linguística, realizar a sua documentação, assumindo a concepção de língua como direito difuso, patrimônio cultural imaterial de todo brasileiro, sendo passível, assim, de registro e memória (FREITAG, 2014).

Instituído pelo Decreto Presidencial no 7.387, de 9 de dezembro de 2010, o INDL tem como objetivo atuar "[...] como instrumento de identificação, documentação, reconhecimento e valorização das línguas portadoras de referência à identidade, à ação e à memória dos diferentes grupos formadores da sociedade brasileira" (BRASIL, 2010, art. 19). O Relatório de Atividades (2006-2007) do Grupo de Trabalho da Diversidade Linguística do Brasil (GTDL) classifica as línguas faladas no Brasil em seis categorias histórico-sociológicas, conforme sua origem histórico-cultural e sua natureza semiótica: indígenas, de comunidades afro-brasileiras, de imigração, de sinais, crioulas e a Língua Portuguesa e suas variações dialetais (GTDL, 2008).

Os conceitos de variedades dialetais da Língua Portuguesa, crioulos e línguas afrobrasileiras não são matéria pacífica, seja na literatura científica, com a discussão acerca dos traços linguísticos limítrofes entre variedades, crioulos e pidgins, seja no âmbito do 
INDL, na medida em que as definições são baseadas em critérios populacionais ou de origem (GTDL, 2008). A falta de clareza pode inviabilizar o processo de identificação, sendo, assim, necessária a proposição de ações que visem clarificar esta distinção considerando não só a perspectiva linguística (descrição da língua), mas também as perspectivas etnográfica (como a comunidade se percebe e se autoidentifica) e jurídica (por tratar-se de elemento constitutivo da diversidade linguística nacional e, portanto, bem de natureza difusa).

Dadas as condições sócio-históricas de formação do Brasil, a região Nordeste é profícua em contatos, dos quais podem decorrer crioulos e variedades afro-brasileiras. A fim de contribuir para o aprimoramento dessas conceituações e subsidiar as ações do processo de "[...] identificação, documentação, reconhecimento e valorização das línguas portadoras de referência à identidade, à ação e à memória dos diferentes grupos formadores da sociedade brasileira" (BRASIL, 2010, art. 1으), nesse texto, discutimos procedimentos de documentação linguística e mapeamento do Português afro-brasileiro, bem como de variedades linguísticas do Português Brasileiro, tanto no plano diatópico quanto no plano diastrático, considerando duas regiões político-administrativas distintas: os estados da Bahia e de Sergipe.

Uma descrição sistemática comparativa entre comunidades afro-brasileiras, especificamente Comunidades Remanescentes de Quilombos (CRQ) dos estados da Bahia e de Sergipe, possibilita o delineamento dos processos históricos de formação das variedades da língua portuguesa do Brasil, permitindo identificar que mudanças foram desencadeadas pelo contato entre línguas, o que impõe a necessidade de que tal descrição parta de fatos da sócio-história das comunidades. 
As comunidades rurais afro-brasileiras são importantes fontes para as pesquisas sobre a realidade sociolinguística atual do Brasil, bem como sobre a sua formação histórica. Essa assertiva baseia-se em dois motivos principais, a saber: pelo fato de o Brasil ter sido, durante muito tempo, um vasto país rural (CUNHA, 1970); e por essas comunidades reunirem fatos característicos da sócio-história do Português Brasileiro, como a expressiva concentração de pessoas de etnia não branca e da ausência ou tardia escolarização da população brasileira. O conceito de Português afro-brasileiro fundamenta-se, não em parâmetros étnicos, mas em parâmetros sócio-históricos:

O Português afro-brasileiro designa aqui uma variedade constituída pelos padrões de comportamento linguístico de comunidades rurais compostas em sua maioria por descendentes diretos de escravos africanos que se fixaram em localidades remotas do interior do país, praticando, até os dias de hoje, a agricultura de subsistência (LUCCHESI, 2009, p. 32).

Embora as comunidades rurais afro-brasileiras tenham algumas peculiaridades gramaticais e lexicais que as singularizem em relação a outras variedades linguísticas, inclusive em relação às variedades populares faladas no Brasil, não se pode generalizar as suas características, pois cada comunidade tem idiossincrasias sócio-históricodemográficas que podem levar a diferenças em termos linguísticos. Embora na Bahia exista uma linha de investigação em CRQ (LUCCHESI; BAXTER; RIBEIRO, 2009; ALMEIDA; CARNEIRO, 2014), em Sergipe, estado espacialmente vizinho, ainda não há estudos sociolinguísticos realizados com dados do Português afro-brasileiro. Na Bahia, além da coleta que embasa a descrição do Português afro-Brasileiro (LUCCHESI; BAXTER; RIBEIRO, 2009), o banco de dados do Projeto A língua Portuguesa do Semiárido Baiano (ARAUJO; ALMEIDA, 2014) é constituído por entrevistas do tipo diálogo entre informante e 
documentador, com diferentes perfis de falantes, provenientes de comunidades rurais e urbanas. Em Sergipe, o banco de dados Falares Sergipanos (FREITAG, 2013, 2017) também reúne amostras constituídas por entrevistas do tipo diálogo entre informante e documentador, mas concentradas ao perfil urbano e escolarizado.

Considerando as características da sócio-história sergipana, e visando à comparabilidade descritiva com os estudos desenvolvidos na Bahia, inicialmente, apresentamos uma proposta de tipologização das CRQ em Sergipe, levando em conta parâmetros sociolinguísticos como os contatos, os deslocamentos e a relação entre o português rural e o português afro-brasileiro. Em seguida, aplicamos a proposta de classificação apresentada a uma CRQ específica, a de Pirangi.

\section{Critérios para a documentação de CRQ: sócio-história e representatividade}

A estratificação de uma amostra para a descrição linguística aos moldes da Sociolinguística costuma seguir critérios metodológicos que visam possibilitar a comparabilidade de resultados (FREITAG, 2018), embora nem sempre se consiga adotar procedimentos que garantam a aleatoriedade da amostra. Para a descrição linguística, costuma-se parametrizar categorias sociodemográficas amplas, como escolarização, faixa etária, sexo/gênero, faixa de renda, dentre outras. No caso da documentação do Português afro-brasileiro, um critério a ser adotado é o da representatividade. Tal critério será adotado tanto na seleção das CRQ quanto na dos falantes.

Para Lucchesi, Baxter e Ribeiro (2009), as CRQ mais representativas do Português afro-brasileiro são as [+ isoladas] e [+ afrodescendentes], pois quanto maiores forem o 
isolamento da comunidade e a proporção de afrodescendentes diretos nela, maior será o grau de interferência da transmissão linguística irregular (desencadeada em situações de contato linguístico massivo) na formação da variedade linguística falada por seus moradores.

Para a documentação linguística em Sergipe, propomos estender o critério de representatividade de Lucchesi, Baxter e Ribeiro (2009), de comunidades [+ isoladas] e [+ afrodescendentes], para [ \pm isoladas], [+ afrodescendentes], [+ africanizadas] e localizadas em municípios (microáreas) e regiões (macroáreas) que foram, nos períodos colonial e imperial, [+ escravocratas]. O fato de uma comunidade quilombola ser [+ afrodescendente] nem sempre a torna [+ africanizada], pois seus proprietários (os residentes e os não residentes) podem não ver os ancestrais africanos e afro-brasileiros como grupo de referência. As comunidades cuja maioria dos quilombolas é adepta de religiões de matriz judaico-cristã (da religião Protestante Evangelicalista, principalmente) exemplificam isso: geralmente são [- africanizadas].

Para a situação de Sergipe, constatamos que as comunidades [ \pm isoladas], [+ afrodescendentes], [+ africanizadas] e localizadas em municípios e regiões sergipanos que foram, nos séculos XVIII e XIX, [+ escravocratas] - que importaram, nesses séculos, grandes quantitativos de escravizados afro-brasileiros e africanos - conservam, em maior grau, os costumes e tradições de seus fundadores ou dos antepassados desses, assim como as comunidades [+ isoladas] e [+ afrodescendentes] baianas analisadas por Lucchesi, Baxter e Ribeiro (2009). Por hipótese, assim como conservam, em maior grau, a cultura de seus fundadores ou dos seus antepassados, preservam, em maior medida, os seus usos linguísticos. 
Na medida em que, em Sergipe, não há comunidade quilombola rural [+ isolada] — todas as rurais têm acesso, em maior ou em menor grau, aos meios de comunicação de massa e aos centros urbanos do estado - , a amostragem se restringe a comunidades rurais [ \pm isoladas], [+ afrodescendentes], [+ africanizadas] e localizadas em municípios e regiões que foram, nos séculos XVIII e XIX, [+ escravocratas].

Como, nessas CRQ, não se fala somente o Português afro-brasileiro - nelas há, também, os quilombolas que, influenciados pelo contato inter-rural/intergrupal, falam, de modo alternado, o Português afro-brasileiro e outra(s) variedade(s) do Português popular rural brasileiro (alternância de variedades); e os que, influenciados pela mídia, pela escola e pelos contatos inter-rural/intergrupal e extrarrural/extragrupal, falam, de maneira alternada, o Português afro-brasileiro, outra(s) variedade(s) do Português popular rural brasileiro e a norma urbana culta -, não convém selecionarmos aleatoriamente os falantes representativos dessa variedade linguística. Para selecioná-los, consideramos os deslocamentos e os contatos dos quilombolas - os fluxos migratórios inter-rurais (entre a comunidade e os povoados circunvizinhos) e extrarrurais (entre a comunidade e as zonas rurbana e urbana dos municípios sergipanos) -, e os sentimentos e as atitudes (positivas ou negativas) desses frente à comunidade.

Quilombolas que nasceram, cresceram e vivem na comunidade, e que gostam dela e querem viver nela, são os falantes mais representativos do Português afro-brasileiro. Estudos sociolinguísticos de orientação variacionista que investigaram os deslocamentos e os contatos dos falantes, e as reações subjetivas desses frente a sua comunidade (cf. LABOV, 2008 [1972]; BATTISTI, 2014) evidenciam que aqueles que nasceram, cresceram e vivem na comunidade, e que gostam dela e querem viver nela, inclusive os mais jovens, 
preservam, em maior medida, os usos linguísticos (do nível lexical ao pragmático-

discursivo) de seus ancestrais, pois veem-nos como grupo de referência.

Vejamos a aplicação desta proposta de representatividade no cenário sergipano, a seguir.

\section{Certificação e regularização fundiária das comunidades quilombolas: identidade e autodefinição}

A Fundação Cultural Palmares (FCP), instituição voltada para promoção e preservação da arte e da cultura afro-brasileiras, formaliza, há 30 anos, a existência das CRQ no território brasileiro, emitindo a certidão de autodefinição (documento que reconhece os direitos dos quilombolas) às comunidades que se autodefinem como "[...] grupos étnicos raciais [...] com trajetória histórica própria, dotados de relações territoriais específicas, com presunção de ancestralidade negra relacionada com formas de resistência à opressão histórica sofrida." (FCP, 2007). Mais de 3.000 comunidades quilombolas brasileiras já receberam a certidão (certificação).

Há, no estado de Sergipe, 33 comunidades remanescentes de quilombos certificadas e 3 com processo de certificação aberto (em análise técnica). Distribuídas em 29 municípios, as comunidades concentram-se principalmente nas regiões Leste Sergipano (9), Centro-Sul Sergipano (7) e Baixo São Francisco Sergipano (6).

Depois da obtenção da certidão de autorreconhecimento, emitida pela FCP, iniciase, caso a comunidade requeira, o processo de regularização do território quilombola. Até o ano de 2003, competia à fundação supracitada a identificação, o reconhecimento, a delimitação, a demarcação e a titulação das terras ocupadas pelos remanescentes dos 
quilombos. Por força do Decreto Presidencial no 4.887, de 20 novembro de 2003, a competência passou a ser do Instituto Nacional de Colonização e Reforma Agrária (Incra). Em Sergipe, não há, ainda, comunidade plenamente titulada. A maioria tem somente a certidão de autodefinição.

Das 14 comunidades quilombolas sergipanas com processo de regularização territorial aberto no Incra, somente 7 têm o mapeamento de seu território divulgado: Catuabo (município de Frei Paulo), Caraíba e Adjacências (Amparo de São Francisco | Aquidabã | Canhoba | Cedro de São João | Telha), Ladeiras (Japoatã), Luzienses (Santa Luzia do Itanhy), Pirangi (Capela), Pontal da Barra (Barra dos Coqueiros) e Serra da Guia (Poço Redondo). Nosso foco, neste texto, recai sobre a comunidade de Pirangi.

Figura 1 - Mapa de localização da comunidade quilombola Pirangi (Capela/SE)

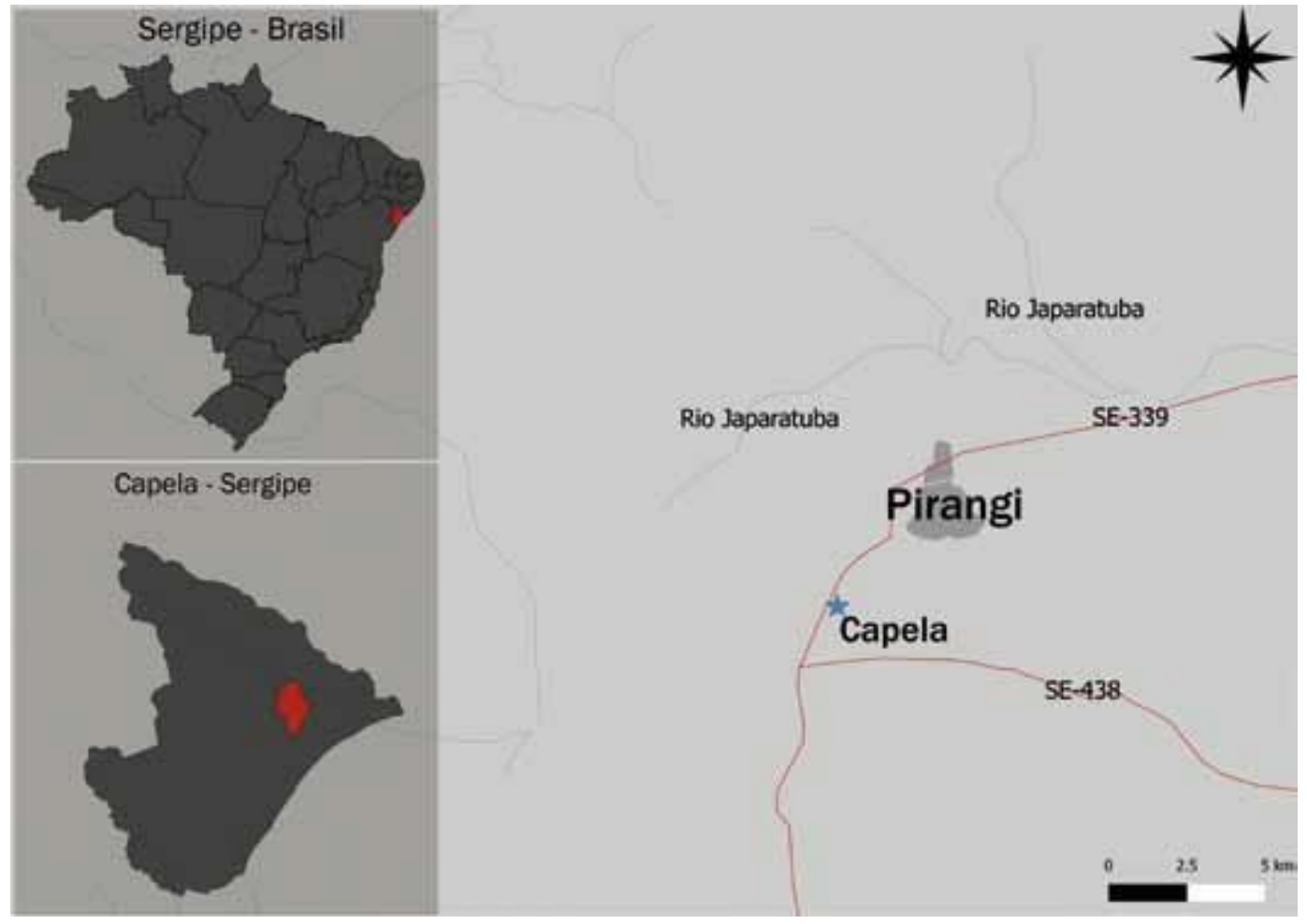

Fonte: FRIZERO (2016, p.1) 
Localizada na bacia do Rio Japaratuba, no município de Capela, e formada por mais de 40 famílias (FRIZERO, 2016, p. 1), a comunidade quilombola Pirangi foi fundada por descendentes diretos dos escravizados que trabalhavam e residiam nos engenhos (adjacentes) Saco da Lagoa (hoje, Fazenda Pirangi) e Saco do Rio (Fazenda Palmeira). Os excertos 1 e 2, extraídos de duas entrevistas concedidas por um dos fundadores da comunidade ao Incra, confirmam essa afirmativa:

(1)

Nasci lá no Saco do Rio, bem na frente do Pirangi. As casas ficavam lá embaixo da fazenda. Era uma senzala; as casas de barro batido na parede e no chão. Minha mãe foi filha de escravo. Sou da família dos negos [(['ne.gus])] de Rufino. Já morreu muita gente. Lá, nos festejos de São João e de Natal, tinha muito samba de coco. (Dona Maria, 86 anos, residente na comunidade quilombola Pirangi. Entrevista concedida em 2010) (FRIZERO, 2016, p. 5, grifo nosso).

(2)

Quando me dei por gente ali chamava assim: Saco da Lagoa. Era o Saco da Lagoa. Nós morávamos ali embaixo, nuns barracos de palha do outro lado da pista. Não tinha pista. Era tudo mato. E vinha pegar água naquela lagoa lá embaixo. (Dona Maria, 87 anos, residente na comunidade quilombola Pirangi. Entrevista concedida em 2011) (FRIZERO, 2016, p. 5).

Diferentemente do que aconteceu em outras comunidades, como na Bahia, cujo passado é mais remoto, a Fazenda Pirangi tornou-se comunidade quilombola no final da década de 1980, quando um grupo de afrodescendentes desempregados e residentes em povoados circunvizinhos ocupou, com o apoio do Sindicato dos Trabalhadores Rurais do Município de Capela e com o da Delegacia do Ministério da Agricultura em Sergipe, suas terras, abandonadas desde 1948 (ano em que foram vendidas ao referido município). Inicialmente, autorizaram-Ihes a cultivar somente lavouras de subsistência, como milho, 
feijão e mandioca, pois o plantio de culturas perenes permitir-lhes-ia pleitear o usucapião das terras (FRIZERO, 2016, p. 9). Na medida em que, no território recém-ocupado, não podiam, também, construir casas, continuaram residindo nos povoados adjacentes: a maioria, em Igrejinha, um dos "[...] mais de 40 povoados de Capela, formados a partir do processo de perambulação dos trabalhadores sem terra" (FRIZERO, 2016, p. 6).

Em 2006, a FCP reconheceu Pirangi como CRQ. Em 2013, o Incra titulou 71,37 dos seus 128,19 hectares. Embora os pirangienses tenham sido reconhecidos como "quilombolas" e tenham obtido posteriormente a posse da maior parte do território, poucos residem nos hectares titulados: a maioria decidiu continuar morando no povoado Igrejinha; e a segunda maior parte, na zona rurbana de Capela. Esse fato pode estar relacionado à relevância da agricultura de subsistência para a maioria dos quilombolas: a construção de muitas casas reduziria a área de plantação e, consequentemente, a produção de alimentos.

O fato de Pirangi ter se tornado comunidade quilombola um século após a abolição da escravidão e o de a maioria de seus proprietários não morar nela tornam-na [ \pm isolada]. Embora seja [ \pm isolada], Pirangi continua sendo [+ africanizada], pois muitos de seus moradores preservam costumes, comportamentos, lendas e crenças dos antepassados. Dona Dulce, líder de um dos dois terreiros de Candomblé (religião predominante) existentes na comunidade, realiza, quinzenalmente, puxada (ritual religioso de matriz africana) e, anualmente, o Caruru de São Cosme e São Damião (festa religiosa sincrética) (FRIZERO, 2016, p. 14). Senhor João Sabino, frequentador do terreiro de Dona Dulce, pratica, regularmente, a Dança de Xangô (uma das danças dos Orixás africanos): “'Gosto de brincar de xangô [...] Tem uma coisa que nasceu comigo. Ninguém botou em mim. Ele já nasceu comigo, é meu mesmo'." (Entrevista concedida em [2011?]) 
(FRIZERO, 2016, p. 13). Senhor Jorge, marido de Dona Dulce, e Washington, seu neto, fazem rezas para a cura de doenças (FRIZERO, 2016, p. 13). As práticas são constitutivas da comunidade, o que tem impactos para a conservação e fortalecimento da identidade linguística, propiciando para um estudo sociolinguístico de comunidades de práticas, uma tendência nos estudos de terceira onda da Sociolinguística (FREITAG; MARTINS; TAVARES, 2012), que já vem sendo desenvolvido em Sergipe (FREITAG; SANTANA; ANDRADE, 2014). A africanização de Pirangi reflete-se, também, no modo como a maioria de seus proprietários cultiva a terra: coletivamente. Esse modo de cultivo é semelhante ao praticado por seus antepassados nos extensos canaviais dos engenhos Saco da Lagoa e Saco do Rio, pois, segundo Schwartz (1988 [1985], p. 127), o trabalho nos campos escravistas brasileiros era, geralmente, realizado em grupos. Durante o processo de abertura dos buracos para o plantio da cana-de-açúcar, por exemplo:

[...] os cativos postavam-se lado a lado. Cada um cavava a terra à sua frente com a enxada, formando uma pequena trincheira. A seguir toda a fileira de escravos (!) recuava e repetia o processo, até que o campo fosse todo revolvido. A labuta era às vezes acompanhada por cantos, para manter o ritmo do grupo, "suavizando o jugo do trabalho" (SCHWARTZ, 1988 [1985], p. 127, grifos nossos).

Essa maneira de agricultar assemelha-se, também, à praticada em alguns quilombos sergipanos (cf. OLIVEIRA, 2010), onde predominava o companheirismo. "Ali, diversos negros fugidos [...] [compartilhavam] suas alegrias, tristezas, derrotas e vitórias" (OLIVEIRA, 2010, p. 47).

Figura 2 - Grupo de trabalho coletivo em Pirangi (Capela/SE) 


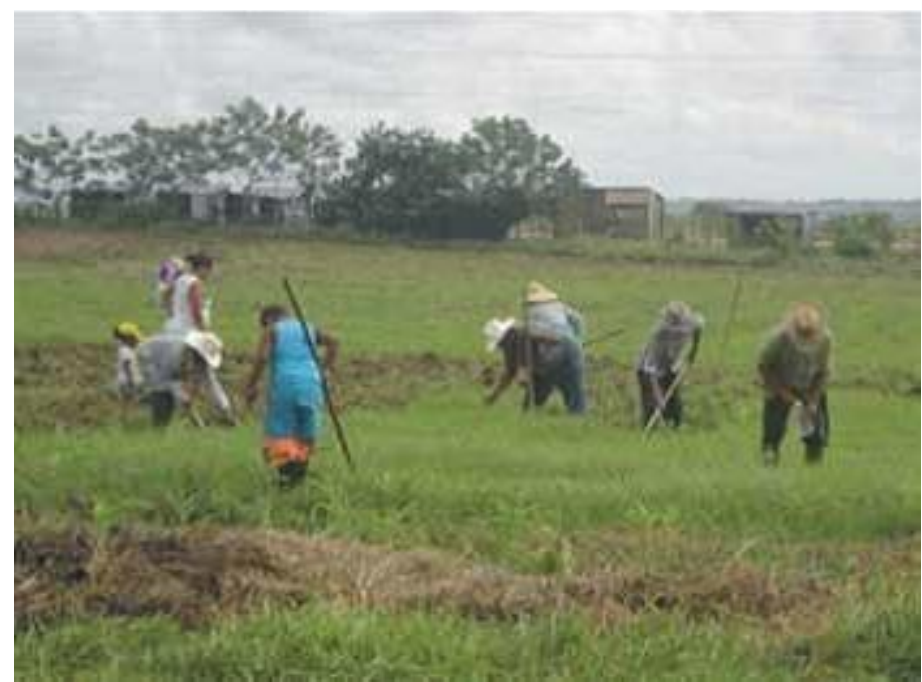

Fonte: FRIZERO (2016, p. 10)

A africanização manifesta-se, ainda, no forte vínculo entre a grande maioria dos moradores dessa comunidade e as memórias da escravidão. Os excertos abaixo (3 e 4), extraídos de duas entrevistas concedidas ao Incra por dois idosos residentes na comunidade, revelam-no:

(3)

Trabalhei nos canaviais, abrindo valeta, cortando cana nos engenhos todos. No Formigueiro ainda fui feitor. A minha avó foi escrava, por parte de mãe. Meu pai trabalhava o dia todo e comia jenipapo... Trabalhava nos engenhos... (Senhor João Sabino, residente na comunidade quilombola Pirangi. Entrevista concedida em 2010) (FRIZERO, 2016, p. 6).

(4)

O meu pai trabalhava no campo, na Fazenda Palmeira, depois foi para o Rezende (Fazenda Rezende), depois na Usina Proveito, Vassouras e Santa Clara. Eu, que trabalhei no campo, plantando cana, cortando... Moramos muito tempo nas terras do (engenho) Saco do Rio (hoje, Fazenda Palmeira)... hoje as casas já caíram tudo. (Senhor Edson Andrade, conhecido como "Pai 'Véio'" e residente na comunidade quilombola Pirangi. Entrevista concedida em 2010) (FRIZERO, 2016, p. 67). 
O vínculo com as reminiscências da escravidão é tão forte, que muitos idosos ainda preservam, na fala, palavras referentes a profissões extintas no final do século XIX, como feitor: "No Formigueiro ainda fui feitor" (FRIZERO, 2016, p. 6); e a construções habitacionais típicas dos períodos colonial e imperial: muitos chamam suas casas de senzalas (FRIZERO, 2016, p. 3). Esse elo com o passado escravocrata provém, certamente: (i) da perambulação de seus antepassados pelas fazendas da região, em busca de trabalho:

Depois da abolição, os ex-escravizados enfrentaram muitas dificuldades para sobreviver e estabelecer moradia autônoma. Mesmo os que permaneceram nos engenhos e fazendas de antigos senhores tinham que procurar trabalho em outras fazendas, percorrendo a pé grandes distâncias (FRIZERO, 2016, p. 5).

(ii) da humilhação desses pelos fazendeiros: “A remuneração era muito baixa, às vezes se restringia a farinha de mandioca e carne seca" (FRIZERO, 2016, p. 5);

(iii) da diáspora dos primeiros descendentes (hoje, os idosos da comunidade) de seus ascendentes libertos do cativeiro, motivada pela irregularidade da oferta de trabalho:

“'A gente ia onde (sic) tivesse cana pra moer. E quando dava, plantava um milho ou outro nos pedaços de terra que o dono deixasse' [...]" (р. 5) / "'A gente tinha que ir onde tinha trabalho. Nós não podíamos morrer de fome'." (p. 6) (Senhor Severino Faustino de Barros, residente na comunidade quilombola Pirangi. Entrevista concedida em [2011?]) (FRIZERO, 2016); e

(iv) da batalha secular pela posse das terras (solos encharcados de suor e sangue afrobrasileiros e africanos) onde os senhores de engenho oprimiram e açoitaram seus ancestrais: "A trajetória de vida dos trabalhadores rurais de Pirangi sempre esteve 
vinculada à terra. Desde muito cedo, aprenderam que ela é fonte de vida." (FRIZERO, 2016, p. 9). Nelas os pirangienses cultivam, hoje, os alimentos que garantem sua sobrevivência e a de suas famílias.

Considerando a documentação linguística e a nossa proposta de tipologização, Pirangi é uma comunidade [ \pm isolada]:

a) [+ afrodescendente]: formada por descendentes diretos de ex-escravizados afro-brasileiros e de ex-escravizados africanos;

b) [+ africanizada]: a maioria de seus membros mantém forte vínculo com a cultura dos antepassados e com as reminiscências da escravidão;

c) Localizada em um município que, no século XIX, sediou mais de 100 engenhos produtores de açúcar (microárea [+ escravocrata]) (FRIZERO, 2016);

d) Localizada no território da antiga região de Cotinguiba: região que sediou, na segunda metade do século XVIII e no XIX, a maior quantidade de engenhos produtores de açúcar sergipanos (macroárea [+ escravocrata]) (AMARAL, 2012).

Tais particularidades sócio-histórico-demográficas contribuem para a manutenção de fenômenos típicos do Português afro-brasileiro na fala dos moradores dessa comunidade, sobretudo na dos que nasceram, cresceram e vivem nela, e que gostam dela e querem viver nela. É um campo ainda a ser investigado, para o qual demanda a documentação sociolinguística.

\section{Considerações finais}

Neste artigo, chamamos a atenção para a importância da documentação e mapeamento do português falado em CRQ rurais sergipanas, destacamos a relevância da 
realização de pesquisas regionais com o desenvolvimento de métodos específicos para as regiões em foco, apresentando uma proposta de classificação das CRQ sergipanas, e aplicamos a referida proposta à comunidade quilombola Pirangi. Esperamos que a proposta de tipologização apresentada neste texto contribua para o reconhecimento do Português afro-brasileiro, variedade linguística desprestigiada pelos falantes da norma culta urbana, pela mídia e pela escola, como Patrimônio Cultural Imaterial do Brasil, para que seja respeitado e valorizado, como direito difuso que é a língua.

\section{Referências}

ALMEIDA, Norma Lucia Fernandes de; CARNEIRO, Zenaide Oliveira Novais. (orgs.). Variação linguística no semiárido baiano. Feira de Santana: UEFS Editora, 2014.

AMARAL, Sharyse Piroupo do. Um pé calçado, outro no chão: liberdade e escravidão em Sergipe (Cotinguiba, 1860-1900). Salvador: EDUFBA; Aracaju: Editora Diário Oficial, 2012.

ARAUJO, Silvana Silva de Farias; ALMEIDA, Norma Lucia Fernandes de. O projeto A língua portuguesa no semiárido baiano - Fase 3: critérios de constituição e da amostragem do Banco de dados. In: FREITAG, Raquel Meister Ko. (org.). Metodologia de coleta e manipulação de dados em Sociolinguística. São Paulo: Blücher, 2014, p. 27-47.

BATTISTI, Elisa. Redes sociais, identidade e variação linguística. In: FREITAG, Raquel Meister Ko. (org.). Metodologia de coleta e manipulação de dados em Sociolinguística. São Paulo: Blücher, 2014. p. 79-98.

BRASIL. Presidência da República. Casa Civil. Subchefia para Assuntos Jurídicos. Constituição da República Federativa do Brasil de 1988. Disponível em: <http://www.planalto.gov.br/ccivil 03/constituicao/constituicao.htm>. Acesso em: 16 maio 2018.

BRASIL. Presidência da República. Casa Civil. Subchefia para Assuntos Jurídicos. Decreto no 4.887 , de 20 de novembro de 2003. Regulamenta o procedimento para identificação, reconhecimento, delimitação, demarcação e titulação das terras ocupadas por remanescentes das comunidades dos quilombos de que trata o art. 68 do Ato das Disposições Constitucionais Transitórias. Disponível em: 
<http://www.planalto.gov.br/ccivil_03/decreto/2003/d4887.htm>. Acesso em: 15 abr. 2018.

BRASIL. Presidência da República. Casa Civil. Subchefia para Assuntos Jurídicos. Decreto no 7.387, de 9 de dezembro de 2010. Institui o Inventário Nacional da Diversidade Linguística e dá outras providências. Disponível em:

<http://www.planalto.gov.br/ccivil 03/ Ato2007-2010/2010/Decreto/D7387.htm>.

Acesso em: 21 abr. 2018.

CUNHA, Celso. Gramática moderna. Belo Horizonte: Bernardo Álvares, 1970.

FREITAG, Raquel Meister Ko. Banco de dados falares sergipanos. In: Working Papers em Linguística. Florianópolis: PPGLg-UFSC, v. 14, n. 2, 2013, p. 156-164.

FREITAG, Raquel Meister Ko; MARTINS, Marco Antonio; TAVARES, Maria Alice. Bancos de dados sociolinguísticos do português brasileiro e os estudos de terceira onda: potencialidades e limitações. Alfa: Revista de Linguística. São José do Rio Preto: PROPeUnesp, v. 56, n. 3, 2012, p. 917-944.

FREITAG, Raquel Meister Ko; SANTANA, Cristiane Conceição; ANDRADE, Thaís Regina Conceição. Práticas constitutivas do povoado Açuzinho. Ambivalências. São Cristóvão: PPGS-UFS, v. 2, n. 3, 2014, p. 194-217.

FREITAG, Raquel Meister Ko. Documentação Linguística de comunidades de práticas. In: Seminário Ibero-Americano de Diversidade Linguística, 11., 2014. Foz do Iguaçu. Anais do Seminário Ibero-americano de Diversidade Linguística. Brasília: IPHAN, 2014. p. 181-185. Disponível em: <https://dspace.unila.edu.br/123456789/3606>. Acesso em: 15 abr. 2018.

FREITAG, Raquel Meister Ko. Falares sergipanos. In: ATAÍDE, Cleber, et alii (orgs.). Gelne 40 anos. São Paulo: Blücher, 2017. p. 119-130.

FREITAG, Raquel Meister Ko. Amostras sociolinguísticas: probabilísticas ou por conveniência?. In: Revista de Estudos da Linguagem. Belo Horizonte: Faculdade de Letras/POSLIN-UFMG, v. 26, n. 2, 2018, p. 667-686.

FRIZERO, Mariana Gonçalves. Quilombo Pirangi. Belo Horizonte: FAFICH, 2016.

FCP. Portaria no 98, de 26 de novembro de 2007. Institui o Cadastro Geral de Remanescentes das Comunidades dos Quilombos da Fundação Cultural Palmares, também autodenominadas Terras de Preto, Comunidades Negras, Mocambos, Quilombos, dentre outras denominações congêneres. Disponível em:

<http://www.palmares.gov.br/file/2010/11/legis21.pdf>. Acesso em: 11 abr. 2018. 
FCP. Comunidades Remanescentes de Quilombos (CRQ's). Disponível em:

<http://www.palmares.gov.br/comunidades-remanescentes-de-quilombos-crqs $>$. Acesso em: 11 abr. 2018 (2016-2018). p. 1-3.

GTDL. Relatório de atividades (2006-2007). Disponível em:

$<$ http://portal.iphan.gov.br/uploads/ckfinder/arquivos/12 2\%20Audi\%C3\%AAncia\%20P\% C3\%BAblica\%20Debate\%20Diversidade\%20Lingu\%C3\%ADstica\%20no\%20Brasil.pdf>.

Acesso em: 10 abr. 2018 (2008). p. 1-32.

LABOV, William. Padrões sociolinguísticos. Tradução Marcos Bagno, Maria Marta P.

Scherre e Caroline R. Cardoso. São Paulo: Parábola Editorial, 2008 (1972).

LUCCHESI, Dante. Introdução. In: LUCCHESI, Dante; BAXTER, Alan; RIBEIRO, Ilza (orgs.). $O$ português afro-brasileiro. Salvador: EDUFBA, 2009. p. 27-37.

LUCCHESI, Dante; BAXTER, Alan; RIBEIRO, Ilza. O português afro-brasileiro: as comunidades analisadas. In: LUCCHESI, Dante; BAXTER, Alan; RIBEIRO, Ilza (orgs.). $O$ português afro-brasileiro. Salvador: EDUFBA, 2009. p. 75-100.

OLIVEIRA, Igor Fonsêca de. Os negros dos matos: trajetórias quilombolas em Sergipe Del Rey (1871-1888). 2010. 138 f. Dissertação (Mestrado em História) - Programa de PósGraduação em História Regional e Local, Universidade do Estado da Bahia, Santo Antônio de Jesus.

SCHWARTZ, Stuart B. Segredos internos: engenhos e escravos na sociedade colonial (1550-1835). Tradução Laura Teixeira Motta. São Paulo: Companhia das Letras, 1988 (1985).

Recebido em 13 de agosto de 2018. Aceite em 11 de fevereiro de 2019. 